PROSIDING XXVII DAN KONGRES X PERHAPI 2018

\title{
Analisis Hubungan Antara Peningkatan Travel Speed Truck dengan Match Factor untuk Menunjang Efisiensi Pengoperasian Truck pada Operasi Penambangan Pit Inul East P2B, HATARI Department, PT Kaltim Prima Coal
}

\author{
Wahyu Asmoro Nursandi, ST. ${ }^{1}$ \\ Agus Siswanto, ST. ${ }^{2}$ \\ ${ }^{I}$ Superintendent Production Shift, Hatari Dept, PT. Kaltim Prima Coal, Kutai Timur, 75611, \\ Indonesia \\ ${ }^{2}$ Act. General Superintendent Production, Hatari Dept, PT. Kaltim Prima Coal, Kutai Timur, \\ 75611, Indonesia
}

Sari

Pit Inul East P2B merupakan salah satu area operasional Hatari Department, selain Pit Inul Middle. Berdasarkan plan 2018 material overburden $50.941 \mathrm{kbcm}$ dari Pit Inul East P2B dialokasikan di AB void dump dengan jarak tempuh 4,2 Km. Tantangan besar dalam operasional Pit Inul East adalah dump sequence yang semakin menjauh dan tuntutan untuk menciptakan praktek operasional yang efisien agar tetap menjadi industri pertambangan yang kompetitif. Sebagai persiapan agar Pit Inul East P2B dapat beroperasi sesuai rencana produksi dan cycle time tetap sesuai target, maka pertengahan tahun 2017 technical section Hatari Department menyampaikan gagasan membuat "jalan bebas hambatan" untuk dump truck.

Technical section Hatari Department melakukan kajian secara komprehensif hubungan peningkatan travel speed truck dengan match factor. Tujuan akhir dari analisis tersebut adalah menetapkan guide line jumlah truck yang beroperasi bagi operation, serta menganalisis opportunity melakukan internal park up. Gagasan yang disampaikan oleh technical Hatari adalah menciptakan jalan bebas hambatan dengan panjang $4.2 \mathrm{~km}$ dengan kualitas jalan meminimalkan undulasi dan memisahkan jalur overburden truck dengan jalur kendaraan ringan, bahkan dengan coal truck. Sehingga truck mampu mengoptimalkan kecepatannya dan meminimalkan cycle time. Project travel speed diberi nama "Everest Road" dan ditargetkan awal tahun 2018 dapat digunakan. Dasar pemikiran Project Everest Road adalah rumus kecepatan dan match factor. Dalam rumus match factor, jumlah truck berbanding terbalik dengan cycle time. Kecepatan merupakan jarak tempuh dibagi waktu tempuh (cycle time). Cycle time berbanding terbalik dengan kecepatan, jika kecepatan maksimal tentu akan menghasilkan cycle time minimal. Sehingga dengan travel speed yang optimal akan menghasilkan cycle time minimal dan pengoperasian truck lebih sedikit atau lebih efisien.

Project Everest Road mulai dikerjakan akhir tahun 2017 dan mulai digunakan Januari 2018. Konsekuensi pengoptimalan kecepatan truck tentu akan berimbas akan munculnya debu dan diperlukan penambahan safety control. Untuk mengontrol keselamatan akibat munculnya kenaikan kecepatan truck, maka 
dilakukan Risk Assessment. Sedangkan kontrol aspek lingkungan akibat timbulnya debu tetap mengacu pada Kepmen 1827K/MEM/30/2018, Pengelolaan Lingkungan Hidup Pada Kegiatan Pengangkutan. Selama penggunaan jalur Everest Road mampu menaikkan travel speed menjadi, sehingga menekan cycle time AB void dump 3.79 menit dan Hatari mampu melaksanakan effisiensi internal park up 3 trucks EH4500.

Kata kunci : match factor, cycle time, dan travel speed

*Penulis untuk korespondensi (corresponding author):

E-mail: wahyu.nursandi@kpc.co.id

Tel: +62-549-525436 atau +628 132653043 8, Faksimil: +62-549-2509998

\section{PENDAHULUAN}

Hatari Department merupakan salah satu dari tiga department di Mining Operation Division, PT. Kaltim Prima Coal yang bertugas dalam kegiatan pengupasan overburden dan coal exposed. Area operasional Hatari terbagi menjadi 2 area, west area dan east area. Pada tahun 2018 Hatari Department mempunyai target operasional overburden removal 93.354,85 kbcm, coal exposed 8.827,00 kton, dan cycle time 30,83 menit. Area operasional west area terdiri dari Pit Inul Middle Panel 2 dan Panel 3, serta dumping Tiung dump dan inpit dump B2 floor. Sedangkan east area terdiri dari Pit Inul East Panel 2B, Panel 2B, dan Panel 3, serta dumping $A B$ void dump, inpit dump panel 1, dan inpit dump B2 floor. Berdasarkan plan 2018 material overburden $50.941 \mathrm{kbcm}$ dari Pit Inul East P2B dialokasikan di $\mathrm{AB}$ void dump dengan jarak tempuh 4,2 Km.

Tantangan besar dalam operasional Pit Inul East adalah dump sequence yang semakin menjauh dan tuntutan untuk menciptakan praktek operasional yang efisien agar tetap menjadi industri pertambangan yang kompetitif. Untuk menciptakan praktek operasional yang efisien dan dapat mencapai target cycle time, maka diperlukan hauling road dengan kualitas prima, meminimalkan undulasi dan dapat meningkatkan truck speed. Sebagai persiapan agar Pit Inul East Panel 2B dapat beroperasi sesuai rencana produksi dan cycle time tetap sesuai target, maka pertengahan tahun 2017 technical section Hatari Department menyampaikan gagasan membuat "jalan bebas hambatan" memisahkan dump truck overburden dengan kendaraan ringan dan coal truck. Selanjutnya project tersebut dinamakan "Project Everest Road".

\section{PEMBAHASAN}

Salah satu parameter dalam perhitungan pit wise margin $(P W M)$ adalah cycle time. Peningkatan cycle time akan berdampak pada penurunan nilai PWM, begitu pula sebalikanya. Hal ini mendorong Hatari Department melakukan kajian terkait penurunan cycle time Pit Inul East Panel $2 B$ ke $A B$ void dump dengan memanfaatkan kenaikan truck speed. Selanjutnya melakukan review kembali terhadap jumlah kebutuhan truck berdasarkan perhitungan match factor.

Technical section Hatari Department melakukan kajian secara komprehensif 
hubungan peningkatan travel speed truck dengan match factor. Tujuan akhir dari analisis tersebut adalah menetapkan guide line jumlah truck yang beroperasi bagi operation, serta menganalisis opportunity melakukan internal park up. Gagasan yang disampaikan oleh technical Hatari adalah menciptakan jalan bebas hambatan dengan panjang $4.2 \mathrm{~km}$ dengan kualitas jalan meminimalkan undulasi dan memisahkan jalur truck overburden dengan jalur coal truck dan kendaraan ringan. Sehingga truck mampu mengoptimalkan kecepatannya dan meminimalkan cycle time. Project travel speed diberi nama "Everest Road" dan ditargetkan awal tahun 2018 dapat digunakan. Dasar pemikiran Project Everest Road adalah rumus match factor. Dalam rumus match factor, jumlah truck berbanding terbalik dengan cycle time. Kecepatan merupakan jarak tempuh dibagi waktu tempuh (cycle time). Cycle time berbanding terbalik dengan kecepatan, jika kecepatan maksimal tentu akan menghasilkan cycle time minimal. Sehingga dengan travel speed yang optimal akan menghasilkan cycle time minimal dan pengoperasian truck lebih sedikit atau lebih efisien.

\section{ANALISA}

Selain coal price, operating cost, dan stripping ratio, cycle time termasuk parameter dalam perhitungan pit wise margin $(P W M)$. Peningkatan cycle time akan berdampak pada penurunan nilai PWM, begitu pula sebalikanya. Hal ini mendorong Hatari Department melakukan kajian terkait penurunan cycle time Pit Inul East Panel $2 B$ ke $A B$ void dump dengan memanfaatkan kenaikan truck speed. Selanjutnya melakukan review kembali terhadap jumlah kebutuhan truck berdasarkan perhitungan match factor.

Sensitivity Analysis PWM

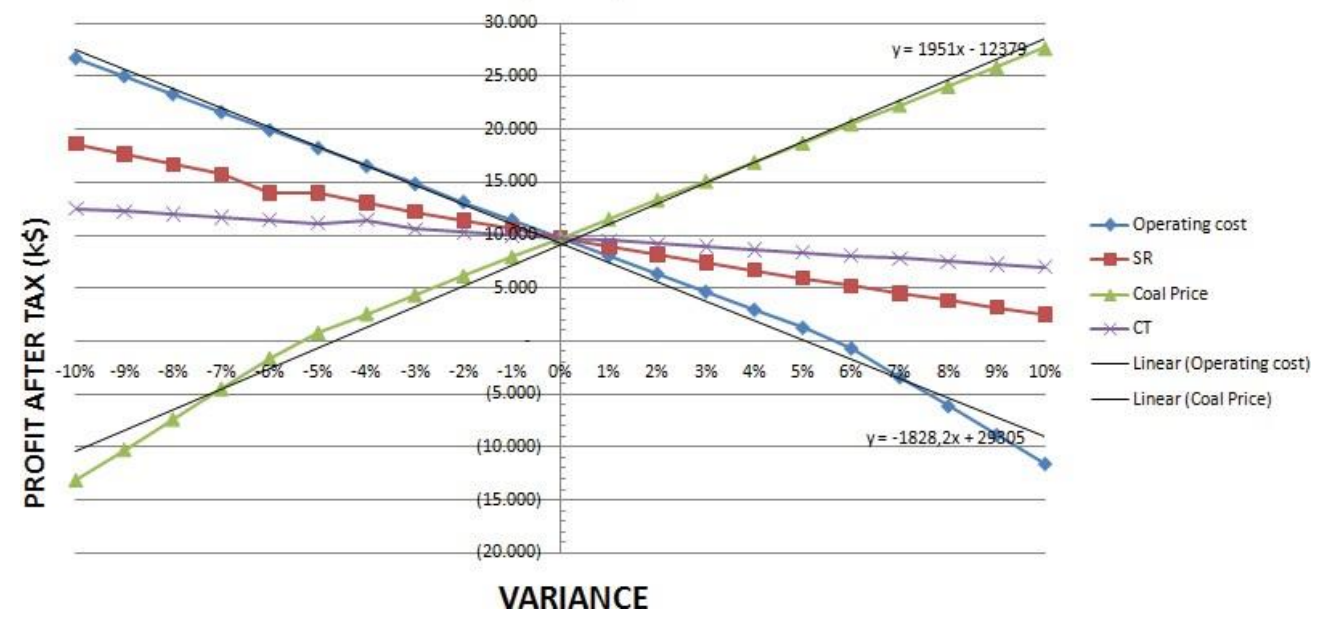

Gambar 1. Grafik Sensitivity Analysis Pit Wise Margin

Analisa tentang travel speed menggunakan rumus dasar kecepatan, kecepatan (V) yaitu perbandingan jarak yang ditempuh (s) dengan waktu yang dibutuhkan (t). Satuan kecepatan adalah $\mathrm{km} / \mathrm{jam}$. Kecepatan yang dimaksud dalam analisis ini merupakan penjumlahan kecepatan untuk rangkaian travelling (empty and full) dan spotting (at dump and loading point), selanjutnya dianalogikan sebagai travel speed. 
Sedangkan waktu tempuh dianalogikan menjadi cycle time dengan satuan menit, cycle time terdiri dari travel time dan spotting time (at dump and loading point). Dengan menggunakan rumus dasar kecepatan, maka akan didapat hubunganantara travel speed dengan cycle time. Setiap kenaikan travel speed akan berbanding terbalik dengan cycle time truck.

Keterangan:

$$
v v=\frac{s s}{t t}
$$

$\mathrm{V}:$ kecepatan $(\mathrm{km} / \mathrm{jam})$

$\mathrm{s}$ : jarak yang ditempuh $(\mathrm{km})$

$\mathrm{t}$ : waktu tempuh yang dibutuhkan (jam)

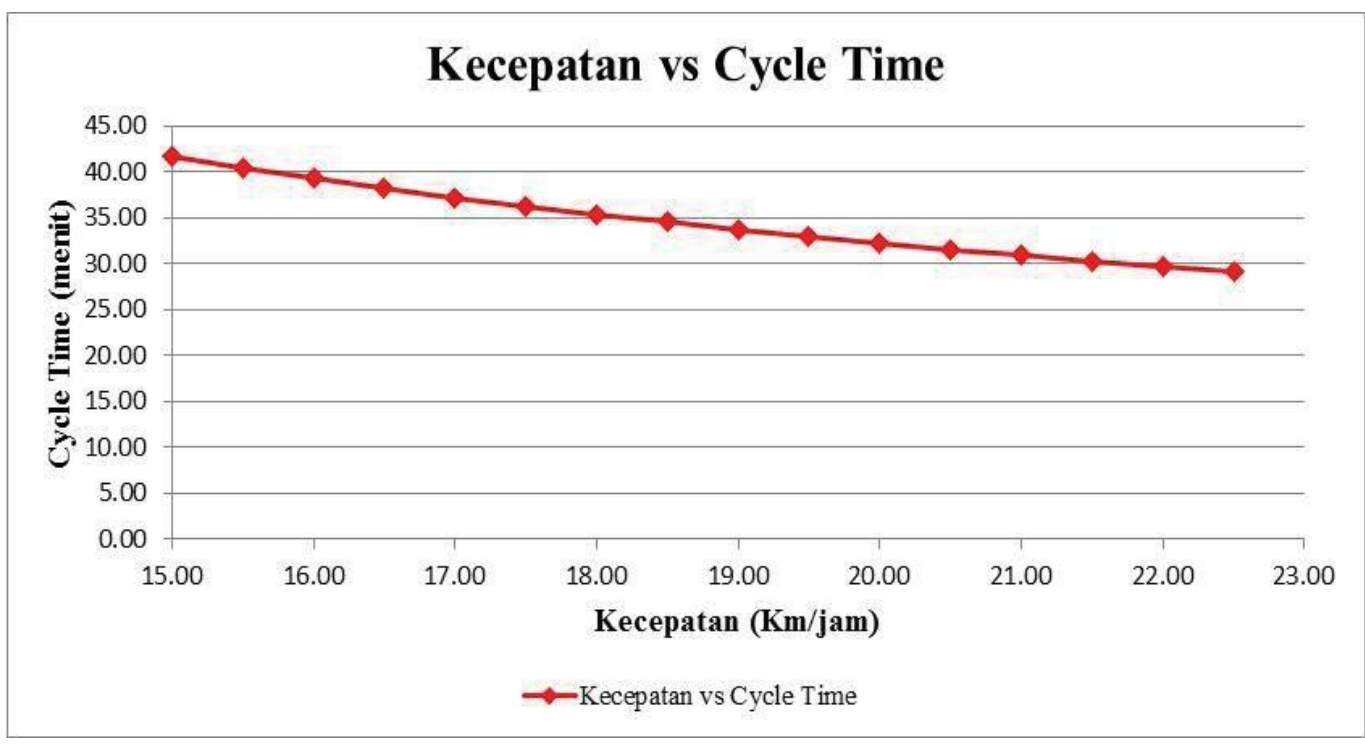

Gambar 2. Grafik Perbandingan Kecepatan vs Cycle Time

Perhitungan simulasi kenaikan cycle time berdasarkan kenaikan kecepatan dengan jarak tempuh konstan 4,7 km (penjumlahan jarak hauling road 4,2 km dengan jarak loading point dan dumping point $0.5 \mathrm{~km}$ )

Selanjutnya data perhitungan cycle time yang diperoleh dari simulasi peninggkatan travel speed menggunakan rumus dasar kecepatan, dihubungkan kembali dengan rumus match factor. Cycle time hasil simulasi peningkatan travel speed dikembangkan kembali menggunakan rumus match factor untuk menghitung jumlah truck yang dibutuhkan. Angka match factor ditetapkan adalah 0,85 dengan pertimbangan adanya kegiatan fix up loading point. Pemilihan tipe alat yang disimulasikan berdasarkan plan dumping allocation, material overburden removal digger Liebherr R996S dan R9800B dialokasikan ke AB void dump. Simulasi keserasian menggunakan sampel Liebherr shovel R996S vs dump truck EH4500/5000 dan Liebherr back hoe R9800B vs dump truck EH4500/5000. 


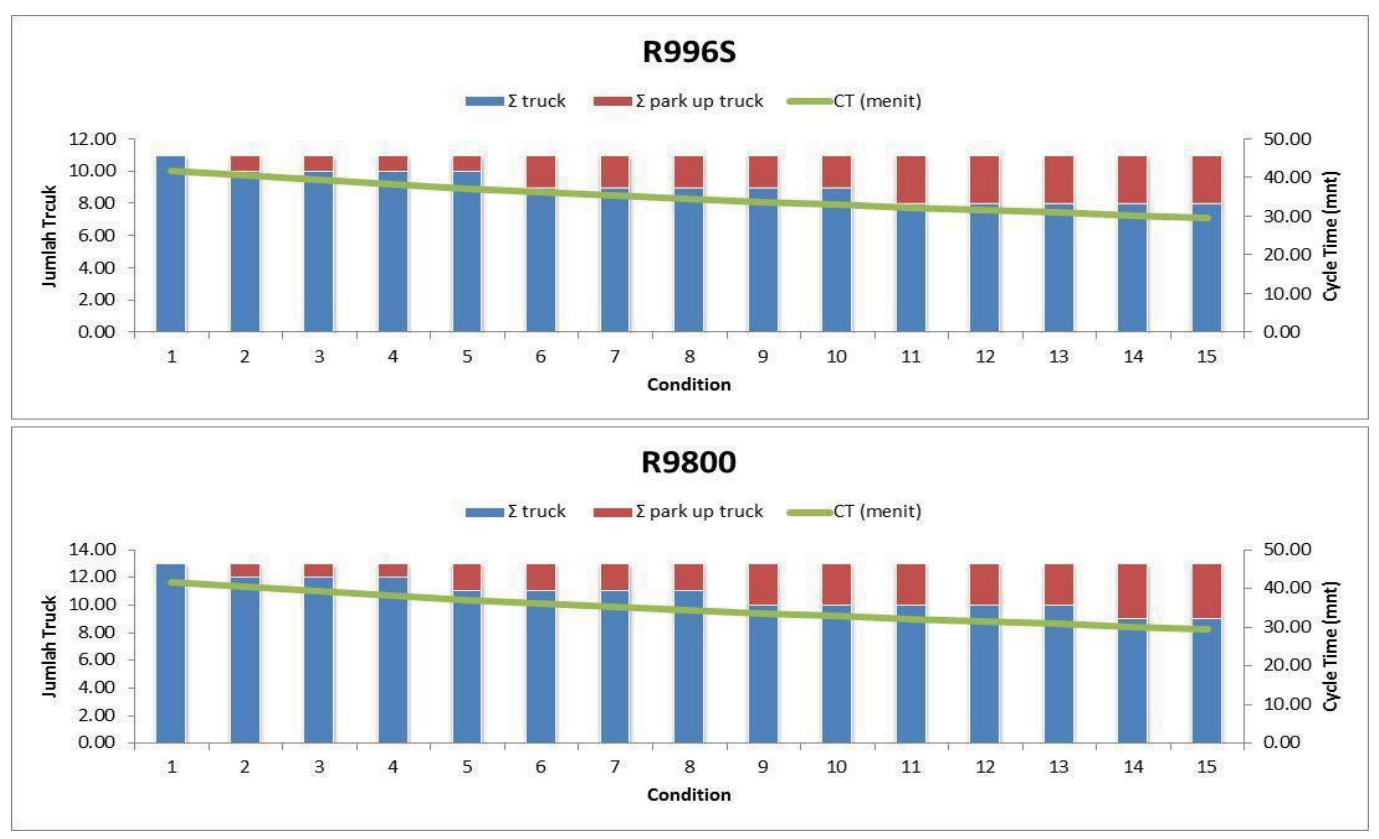

Gambar 3. Grafik Perbandingan Kebutuhan Truck vs Cycle Time

Plan spot load Liebherr R996S vs EH4500/5000 adalah 3,31 menit, sedangkan $R 9800 B$ vs EH4500/5000 adalah 2,75 menit. Untuk cycle time 41,60 menit dan match factor 0,85, perhitungan jumlah truck yang dibutuhkan untuk melayani Liebherr R996S adalah 11 truck, sedangkan Liebherr R9800B adalah 13 truck. Dalam rumus perhitungan match factor, cycle time berbanding lurus dengan jumlah truck. Semakin tinggi cycle time, semakin banyak jumlah truck yang dibutuhkan. Sebaliknya jika cycle time menurun, kebutuhan truck juga menurun. Sehingga truck yang berlebih bisa dilakukan park up, sebagai bagian effisiensi.

\section{Match factor : $\Sigma$ Truck $x$ (Spotting time + loading time) Cycle time}

Jika travel speed dihubungkan dengan match factor mempunyai hubungan sebagai berikut: travel speed $(v)$ akan mempengatuhi cycle time $(t)$ dalam rumus kecepatan, peningkatan travel speed akan mempengaruhi durasi cycle time akan menjadi lebih pendek. Berkurangnya durasi cycle time dalam rumus match factor, akan mempengaruhi jumlah truck yang dibutuhkan. Semakin pendek durasi cycle time, semakin sedikit jumlah truck yang dibutuhkan.

\section{PEMBANGUNAN EVEREST ROAD}

Project Everest Road dirancang untuk menciptakan hauling road dengan meminimalisir undulasi, memisahkan jalur overburden dump truck dengan kendaraan ringan dan coal truck. Sehingga dump truck dapat beroperasi dengan travel speed yang optimal tanpa terganggu dengan perlambatan yang disebabkan undulasi dan gangguan unit lain (kendaraan ringan). Everest Road dirancang dengan lebar 70 meter, terbagi menjadi 3 area (jalur truck bermuatan, jalur truck kosongan, dan jalur kendaraan ringan), terpisah dengan jalur coal truck dan 
terbentang sepanjang 4,2 km. Stage awal dilakukan dumping menggunakan material Pit Inul East sebagai based jalan. Arah dumping mulai dari timur atau pit menuju ke arah barat atau dumping area. Untuk menciptakan permukaan jalan dengan kualitas prima tanpa undulasi, dibutuhkan finishing layering material dengan tingkat kekerasan yang tinggi. Karakteisktik material Pit Inul East mempunyai hasil test UCS(Unconfined Compressive Strength) lebih rendah dibandingkan dengan material Pit Bendili. Maka untuk proses finishing layering permukaan jalan Everest road menggunakan material dari Pit Bendili dengan ketebalan 1,5 meter, total volume $441 \mathrm{kbcm}$.

Setelah lebar jalan telah sesuai, dilajutkan pembuatan tanggul pemisah jalur overburden truck dengan dimensi lebar tanggul 4 meter dan tinggi tanggul 2,5-3 meter. Proses pembangunan saat ini masuk dalam kategori finishing, yaitu pembentungan tanggul tengah jalan connecting jalur kendaraan ringan dengan simpang 3 Andromeda dan $A B$ void dump. Untuk area simpang 3 Andromeda, jalur coal truck dipisah dan dilarang memasuki jalur overburden truck.

Untuk melengkapi kajian resiko yang muncul akibat kenaikan travel speed, Hatari Department bersama team safety Mining Operation Division melakukan kajian secara mendalam dan terdokumentasikan dalam dokumen risk assessment terhadap bahaya yang muncul akibat kenaikan travel speed. Beberapa rekomendasi dari risk assessment adalah menetapkan Everest road sebagai area lalu lintas terbatas, sehingga membatasi kegiatan selain hauling overburden. Tambahan infrastruktur rest area untuk evakuasi jika terjadi kerusakan truck di Everest road, pembagian segment jalan berdasarkan kecepatan truck dan dilengkapi informasi kecepatan yang digunakan dan penetapan lock gear. Menetapkan maksimal kecepatan yang diperbolehkan adalah $40 \mathrm{~km} / \mathrm{jam}$ untuk truck bermuatan dan 60 $\mathrm{km} / \mathrm{jam}$ untuk truck kosongan. Selain sisi safety, Hatari Department juga mengkaji aspek lingkungan timbulnya debu akibat peningkatan travel speed dengan mengacu pada Kepmen 1827K/MEM/30/2018, Pengelolaan Lingkungan Hidup Pada Kegiatan Pengangkutan.

\section{HATARI EVEREST ROAD - design}

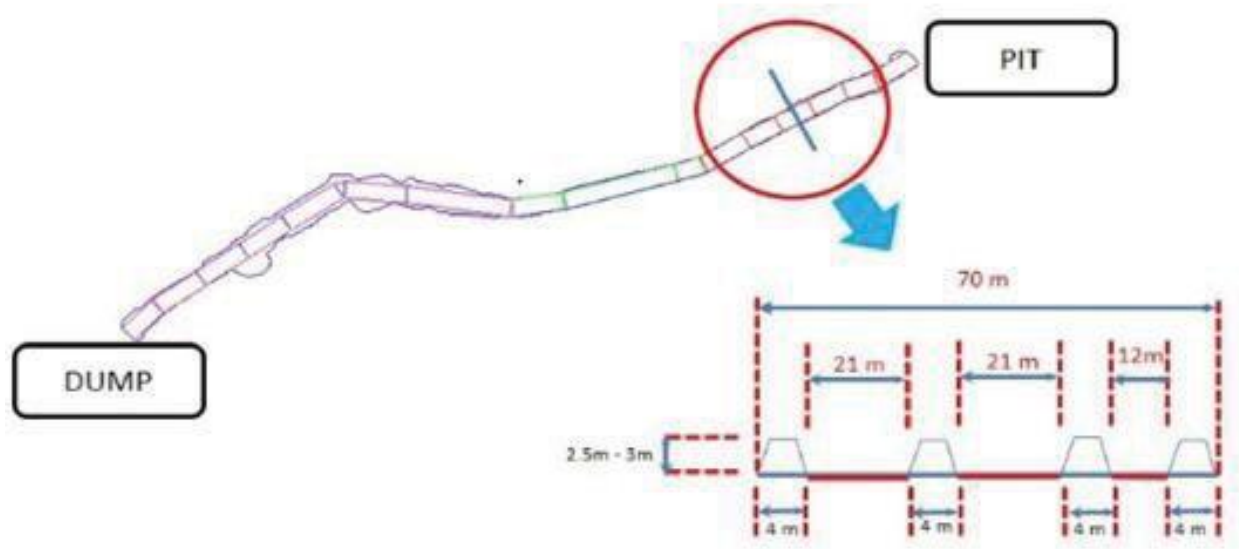

Gambar 4. Design Dimensi Pembagian Jalur Everest Road 


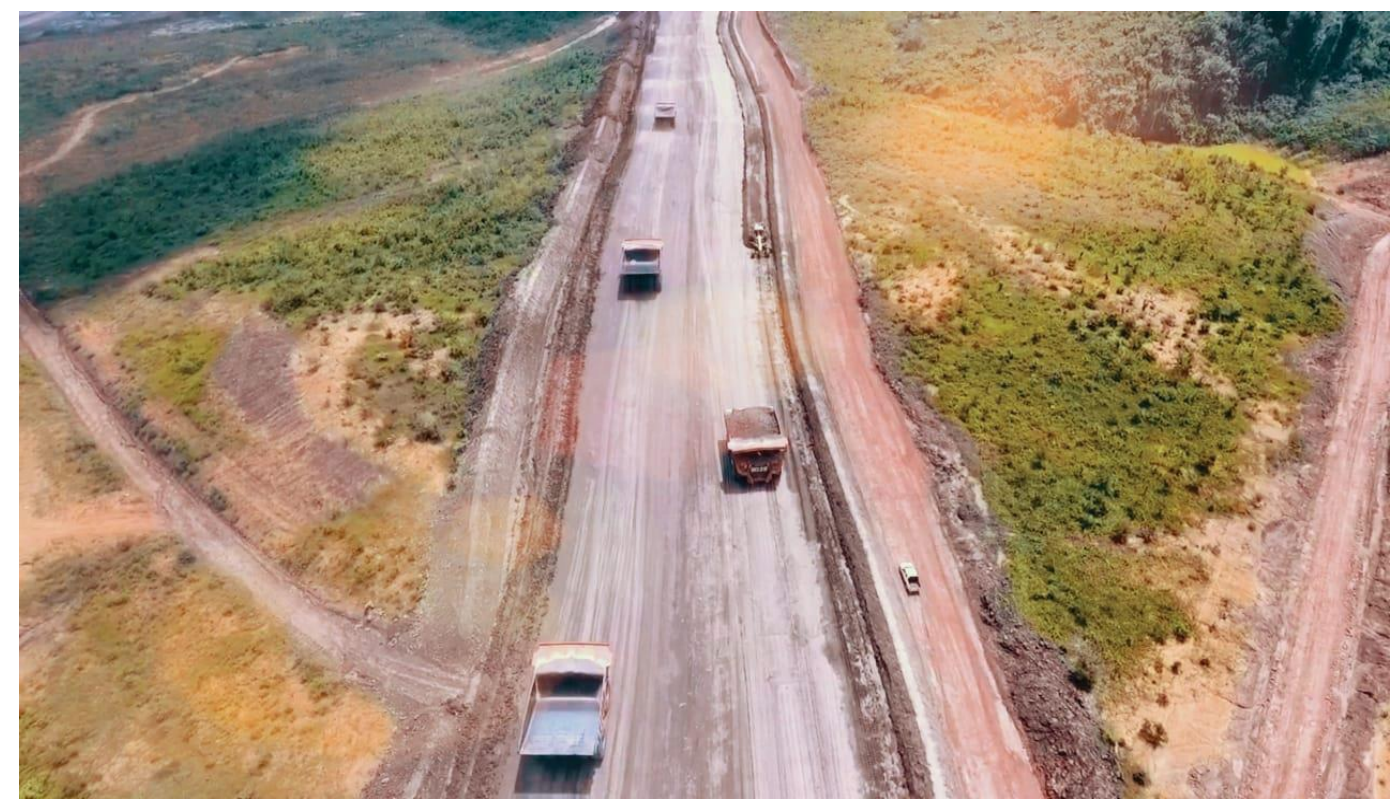

Gambar 5. Foto Udara Kondisi Actual Everest Road

\section{PERHITUNGAN COST EFFICIENCY DAN PENCAPAIAN TARGET PRODUKSI}

Penurunan jumlah truck yang dibutuhkan dalam operasi penambangan Pit Inul East panel $2 B$, tentu memicu timbulnya opportunity untuk melakukan effisiensi dengan cara memarkir truk (park up). Effisiensi truck dengan memarkir truck dapat terwujud dengan peningkatan travel speed, salah satu faktor yang berpengaruh dalam peningkatan travel speed adalah kualitas jalan. Proses finishing layering permukaan jalan Everest road menggunakan material import dari Pit Bendili dengan ketebalan 1,5 meter, lebar 70 meter, panjang 4,2 km, dan total volume $441 \mathrm{kbcm}$. Biaya tambahan yang muncul dalam Project Everest Road adalah pengambilan material layering dari Pit Bendili.

Seiring dengan progress pembangunan Project Everest Road, mulai terjadi peningkatan travel speed. Target minimum travel speed adalah $17 \mathrm{~km} / \mathrm{jam}$, saat ini pencapaian tertinggi travel speed adalah $22 \mathrm{~km} / \mathrm{jam}$. Berdasarkan analisis di atas, utnuk travel speed $17 \mathrm{~km} / \mathrm{jam}$, Hatari Department mempunyai opportunity parkup 3 truck EH4500(1 truck dari R996S dan 2 truck dari R9800). Komponenoperating cost yang diperhitungkan adalah fuel cost dan tyre cost. Sehingga dengan memarkir 3 dump truck EH4500 selama 9 bulan dibandingkan biaya proses layering jalan Everest road, maka biaya penghematan yang muncul adalah US\$ 1,868,160. Program internal park up 3 EH4500 karena peningkatan travel speed Hatari Department tidak mempengaruhi pencapaian target $O B$ removal. Hal ini dibuktikan dengan perhitungan perbandingan $O B$ removal by digger vs $O B$ removal by truck. Hatari Department tetap mengambil opportunity park up 3 EH4500, meskipun muncul variance $O B$ removal by digger vs $O B$ removal by truck $(-1,266,136 \mathrm{bcm})$. Karena saat uji coba penggunaan Everest road minimum target travel speed 17 $\mathrm{km} / \mathrm{jam}$ hampir selalu terpenuhi. Actual travel speed saat ini 17,5-22 km/jam. 


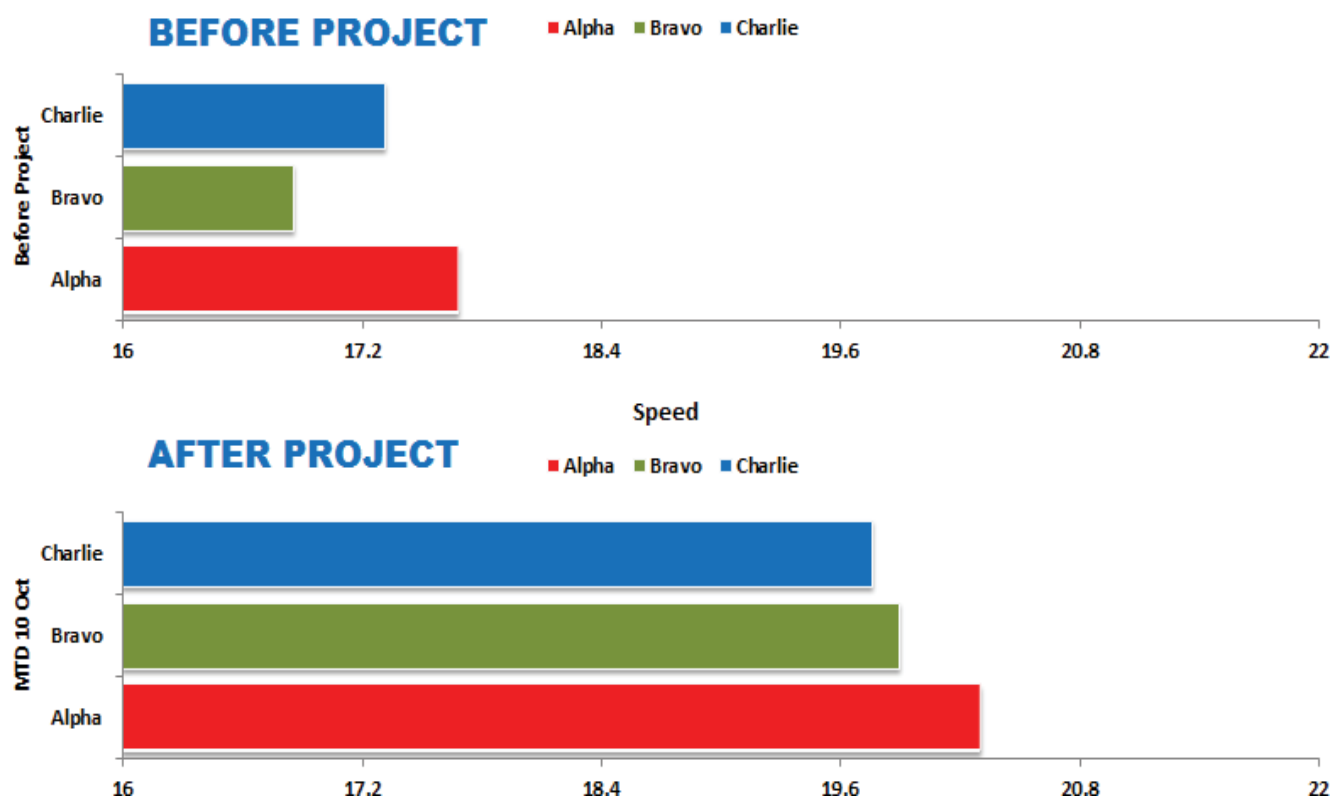

Gambar 6. Perbandingan travel speed sebelum dan sesudah Project Everest Road

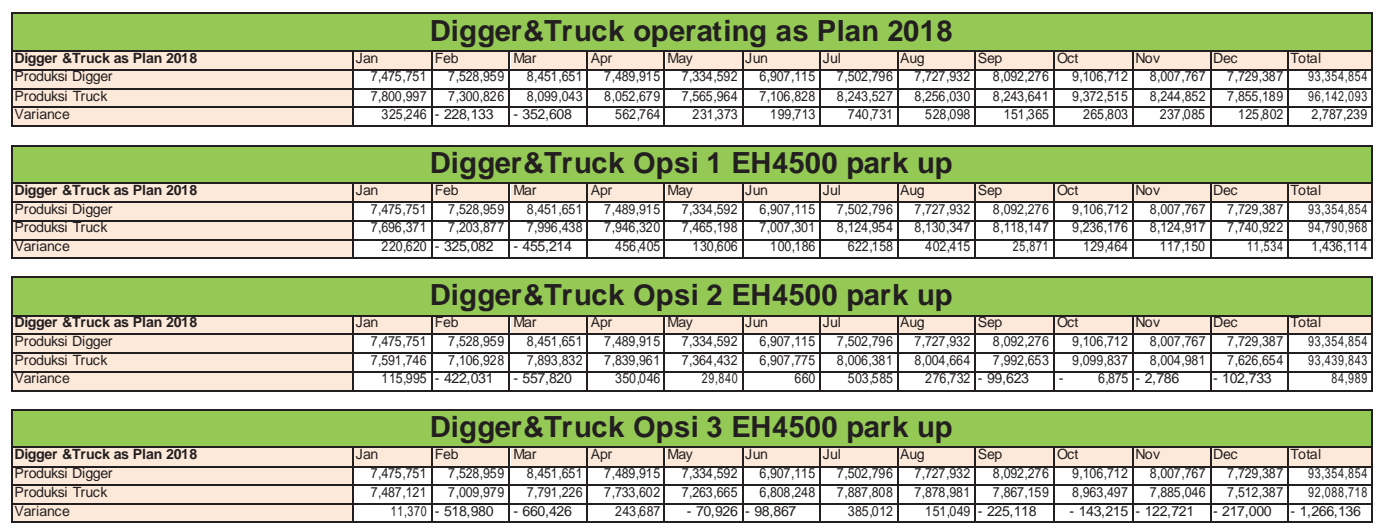

Tabel 1. Perhitungan Variance OB Removal by Digger vs OB Removal by Truck

\section{KESIMPULAN}

Project Everest Road mempunyai dampak significant dalam praktek operasional Pit Inul East, Hatari Department antara lain:

1. Hubungan travel speed dengan match factor dapat dikaitkan menggunakan rumus dasar kecepatan dan selanjutnya dihubungkan dengan cycle time dalam rumus match factor.

2. Kenaikan travel speed berbanding terbalik dengan cycle time, penurunan cycle time berbanding lurus dengan penurunan kebutuhan jumlah truck. Sehingga membuka peluang untuk melakukan effisiensi dengan memarkir beberapa truck. 
3. Optimalisasi travel speed dapat dilakukan dengan membangun infrastruktur dengan konsep memisahkan jalur overburden truck, coal truck dan kendaraan ringan. Serta memperbaiki kualitas permukaan jalan untuk meminimalkan undulasi.

4. Biaya tambahan yang timbul dari kegiatan layering material dari Pit Bendili lebih murah US\$1,868,160 dibandingkan mengoperasikan 3 truck EH4500.

5. Hatari Department tetap mengambil opportunity Park up 3 EH4500, meskipun muncul variance $O B$ removal by digger vs $O B$ removal by truck. Karena saat uji coba penggunaan Everest road minimum target travel speed $17 \mathrm{~km} / \mathrm{jam}$ hampir selalu terpenuhi. Actual travel speed saat ini 17,5 $-22 \mathrm{~km} / \mathrm{jam}$.

6. Perlu dilakukan kajian tentang safety terhadap dampak kenaikan travel speed truck pada jalur Everest road. Maka dilakukan risk assessment untuk melakukan kajian identifikasi bahaya dan penilaian resiko kenaikan travel speed Everest road. Rekomendasi yang muncul antara lain menetapkan Everest road sebagai area lalu lintas terbatas, sehingga membatasi kegiatan selain hauling overburden, tambahan infrastruktur rest area untuk evakuasi jika terjadi kerusakan truck di Everest road, pembagian segment jalan berdasarkan kecepatan truck dan dilengkapi informasi kecepatan yang digunakan dan penetapan lock gear, maksimal kecepatan yang diperbolehkan adalah $40 \mathrm{~km} / \mathrm{jam}$ untuk truck bermuatan dan $60 \mathrm{~km} / \mathrm{jam}$ untuk truck kosongan.

7. Hatari Department menetapkan minimal 2 water truck beroperasi di area Everest road untuk meminimalkan dampak aspek lingkungan(timbulnya debu) akibat peningkatan travel speed dengan mengacu pada Kepmen 1827K/MEM/30/2018, Pengelolaan Lingkungan Hidup Pada Kegiatan Pengangkutan.

8. Dampak intangible dari Project Everest Road adalah efek ergonomic dalam pengoperasian truck, karena kualitas jalan dengan meminimalisir undulasi.

\section{DAFTAR PUSTAKA}

1. PT. Kaltim Prima Coal. 2017. Prima Nirbhaya Fatality Prevention Element 1.09 Haul Road Manual, Sangatta: PT. Kaltim Prima Coal.

2. Kementrian Energi dan Sumber Daya Mineral Republik Indonesia. 2018. Kepmen 1827K/MEM/30/2018, Jakarta: Kementrian Energi dan Sumber Daya Mineral Republik Indonesia. 
